\title{
Double-sided open split ring resonator for compact microstrip band- pass filter design
}

Juan de Dios Ruiz Juan Hinojosa

Departamento de Electrónica y Tecnología de Computadoras, Universidad Politécnica de Cartagena, Plaza del Hospital n¹, 30202 Cartagena (Murcia), Spain

E-mail: juan.hinojosa@upct.es

Abstract: A metamaterial structure, called the double-sided open split ring resonator (DOSRR), which combines two open split ring resonators (OSRRs) aligned over the opposite faces of the substrate in an inverted fashion is presented. A study of this resonator from full-wave electromagnetic and circuit simulations is performed. As with the OSRR cell, the DOSRR cell allows a series connection along a microstrip transmission line and it has a small electrical size. Moreover, the DOSRR cell has the ability to add a transmission zero in the out-of-band region without increasing its size. This DOSRR cell is used for the design of compact microstrip slow-wave type bandpass filters. Two strategies based on circular windows etched in the bottom plane instead of square windows and U-shape slots etched in the microstrip transmission line are designed to increase the stop band and to add extra zeros in order to suppress the spurious band. The experimental results have confirmed the possibilities of this electrically small resonator (DOSRR) and the efficiency of both strategies to improve the out-of-band rejection.

Index Terms - Band-pass filters; Microstrip filters; Resonators 


\section{Introduction}

In recent years, the split ring resonator (SRR), the complementary split ring resonator (CSRR), the open version of the SRR (OSRR) and the open complementary split ring resonator (OCSRR) have attracted much interest because of the possibility to apply such structures to planar technology and their potential applications in compact microwave components [1-11].

Different strategies have been developed in recent years for the design of planar band-pass filters with SRRs and CSRRs [12]. One of the first strategies was the inclusion of SRRs close to the coupled-line sections in coupled-line band-pass filters. In these filters, the SRRs eliminate the spurious bands in order to improve the out-of-band rejection, but they do not contribute in the control of the filter characteristics. To obtain propagating media with controllable characteristics, it is necessary to have a host transmission line loaded with SRRs or CSRRs, in combination with other elements such as shunt inductances and series capacitances. Thus, different cells were conceived and applied to the design of band-pass filters based on alternate right/left-handed cells and balanced cells. In the first strategy, the left-handed cells can be implemented as a combination of SRRs etched on the bottom side and shunt inductances etched on the coplanar waveguide, while the right-handed cells consist of the combination of SRRs etched on the bottom side and series capacitances etched on the coplanar waveguide. The combination of these two types of cells provides a transmission zero above and below the first transmission band, and therefore, a band-pass response. In microstrip technology, the structures combine the dual counterparts of the right/left-handed cells used in coplanar technology. In the case of the second strategy, the composite right/lefthanded cells are designed to be balanced. In this case, the series and shunt resonant 
frequencies are equal and there is not a forbidden band between the left-handed and right-handed allowed bands. Thus, the balanced composite right/left-handed cells reveal high-pass behaviour. In this way, it is possible to implement band-pass filters with a wide transmission band. The upper limit of the band can be controlled by adding some resonators or elements, tuned at the frequency of interest, to our design. The design of planar band-pass filters can be obtained by applying a method developed in [13], which cascades transmission line sections, acting as impedance inverters, with resonators in shunt configuration. In general, in both strategies, the resonators are etched on the bottom layer of the transmission line and excited by the magnetic or electric field generated by the line, while the shunt inductances and series capacitances are etched on the top layer of the transmission line.

Among the different kinds of resonators previously mentioned, the OSRR (Fig. 1) is considered as a very interesting component for the design of compact microstrip band-pass filters $[8,9]$. This cell works as lumped $L C$ series elements with a strong coupling between open rings (large capacitance) and presents an electrical size smaller than that corresponding to the SRR and CSRR resonators. Moreover, the OSRR cell allows a series connection along a microstrip transmission line. Two strategies have been applied for the design of band-pass filters with the OSRR cell [8,9]. The first strategy consists in the design of a compact slow-wave type band-pass filter [14] by cascading several OSRRs in series with a microstrip line. The filter specifications such as the resonance frequency, the bandwidth and the depth of the rejection band are controlled by adjusting the dimensions, the length and the number of OSRR cells, respectively. In the second strategy, the design is based on the use of quarter-wave microstrip lines (acting as inverters) with different characteristic impedances connecting 
identical OSRRs. In this case, the impedance of the $\lambda / 4$ inverters must be conveniently calculated to achieve the filter specifications. In practice, for both strategies spurious bands appear at frequencies higher than the transmission band due to the effects of the cascaded OSRR cells and, therefore, they can spoil the performance of the designed band-pass filter.

In this paper, we propose to design compact microstrip slow-wave type bandpass filters. The size of the microstrip band-pass filter and the depth of the rejection band being strongly related with the number of cascaded OSRR cells [8], we suggest the possibility of adding a transmission zero between the pass-band and the spurious band without increasing the size of the unit OSRR cell. This goal can be achieved by using a double-sided OSRR (DOSRR) cell instead of an OSRR cell. The DOSRR cell is inspired by the OSRR cell. It combines two OSRRs aligned over the opposite faces of the substrate in an inverted fashion. Thus, the DOSRR cell allows a series connection along a microstrip transmission line and for the same physical size as the OSRR cell; it has the ability to add a transmission zero above the transmission pole. Moreover, the DOSRR cell, as the OSRR cell, also presents an electrical size smaller than that corresponding to the SRR and CSRR resonators. The application of $N$ cascaded DOSRR cells instead of $N$ OSRR cells yields compact microstrip band-pass filters with $N$ poles and $N$ zeros. The periodical effect of cascaded DOSRR cells causes a spurious band relatively close to the filter band as for the slow-wave type band-pass filters with cascaded OSRR cells [8]. This spurious band can be suppressed by adding a cascaded low-pass filter or stop-band filter to the DOSRR-based microstrip band-pass filter. This additional stage increases the insertion losses and the filter size. In order to overcome these drawbacks, we propose to apply two strategies for the design of DOSRR-based 
microstrip band-pass filters. Both strategies allow one to save filter size and to achieve a wide stop band. The first strategy consists in using the same circular design shape of the DOSRR cell at the bottom and top planes of the circuit. Thus, we substitute the square window etched in the bottom plane of the DOSRR cell by a circular window, which allows us to shift upwards the spurious band. The second approach resides in making Ushape slots in the transmission line, which permits us to add extra controllable transmission zeros to suppress the spurious band [15]. The combination of both strategies for the implementation of compact third-order DOSRR-based microstrip band-pass filters with improved out-of-band performance, as is proposed in this paper, is unique. The possibilities of this electrically small resonator (DOSRR) and the efficiency of both strategies to obtain a wide stop band region are experimentally demonstrated.

\section{DOSRR structure, equivalent circuit model and simulations}

\subsection{DOSRR structure}

The structure of the DOSRR unit cell excited by a microstrip line is presented in Fig. 2. It is conceived from a conventional OSRR cell [8]. At the bottom side, corresponding to the ground plane of the microstrip line, an OSRR cell is etched into the square window without metallization. The top OSRR and bottom OSRR are aligned over the opposite faces of the substrate in an inverted fashion. In this way, the electromagnetic behaviour of the top OSRR cell perturbs the bottom OSRR cell.

\subsection{Equivalent circuit model}

In [8], the authors have shown that the OSRR cell works as lumped $R_{1} L_{1} C_{1}$ series elements (Fig. 1c). The values of $R_{1}$ and $L_{1}$ are the same as for the SRR circuit model 
( $\left.R_{1}=R_{S R R}, L_{1}=L_{S R R}\right)$ with identical dimensions $\left(r, c\right.$ and $d$ ) and substrate $\left(\varepsilon_{r}\right)$, whereas the value of $C_{1}$ is four times the capacitance of the corresponding SRR cell $\left(C_{1}=4 C_{S R R}\right)$. The total distributed capacitance $C_{1}$ between the inner and outer rings of the OSRR can be computed from the series connection of two equal capacitances $\left(2 C_{1}\right)$ associated with each symmetrical halves of the structure. The line of symmetry of the OSRR passes between the gap $g$ of the inner and outer rings as shown in Fig. $1 a$ (dotted line).

As shown previously, as long as the particle is smaller than the operating wavelength, an equivalent circuit model may be used to describe the electromagnetic behaviour of the DOSRR unit cell (Fig. 2). In the same way as the OSRR cell, the outer ring of the top OSRR is excited by the current flowing through the microstrip line, whereas the top inner ring is excited by the displacement current flowing through the slot $d$ between both rings. Therefore, the top OSRR works as lumped $R_{1} L_{1} C_{1}$ series elements (Fig. 2c). In the bottom plane, the outer and inner rings are coupled to the top outer and inner rings by means of distributed capacitances $C_{c, o}$ and $C_{c, i}$. When the two bottom rings are excited, the total distributed capacitance $C_{2}$ between the inner and outer rings can also be calculated from the series connection of two equal capacitances $\left(2 C_{2}\right)$ associated with each symmetrical halves of the bottom structure of inductance $L_{2}$ and resistance $R_{2}$. The line of symmetry of the DOSRR passes between the gap $g$ of the top and bottom rings as shown in Fig. $2 a$ (dotted line). In Fig. $2 c, \varepsilon_{r e f f}$ and $Z_{c}$ represent the effective permittivity and the characteristic impedance of the microstrip line, respectively. $D$ is the length of the DOSRR cell. In this equivalent circuit model, we have omitted some high-order effects (mutual inductances, mutual capacitances, 
etc.). It is possible to take into account all these effects. However, the equivalent model and analytical relationships are more complex and the real benefit, as already occurs for the SRR [16, 17], can be usually considered as minor. The proposed simple equivalent circuit model allows the basic relations between the substrate parameters (relative permittivity and thickness substrate), and the transmission pole $\left(f_{p}\right)$ and transmission zero $\left(f_{z}\right)$ frequencies to be explained.

In order to derive the inductance and capacitance values of the proposed model, we assume that the top and bottom OSRRs have the same dimensions. Thus, the equivalent circuit model of the DOSRR cell is composed of the connection of two identical OSRR $\left(R_{i}, L_{i}\right.$ and $C_{i}$ with $\left.i=1,2\right)$ and capacitances $C_{C, o}$ and $C_{C, i}$, which represent, respectively, the coupling effects of the outer and inner rings printed on opposite faces of the substrate. $R_{1}, L_{1}$ and $C_{1}$ series lumped elements correspond to the top OSRR, whereas the bottom OSRR is modelled by $R_{2}, L_{2}$ and $C_{2}$ series elements. $R_{1}, L_{1}$ and $C_{1}$ values are the same as for the simple OSRR circuit model with identical substrate and dimensions [8]: $R_{1}=R_{O S R R}, L_{1}=L_{O S R R}$ and $C_{1}=C_{O S R R} \cdot R_{2}, L_{2}$ and $C_{2}$ values are equal to respective $R_{1}, L_{1}$ and $C_{1}$ values (we will refer to them as $R, L$ and $C$ ), since the bottom OSRR is identical to the top OSRR. The values of $C_{C, o}$ and $C_{c, i}$ can be computed by using the following relationships:

$$
\begin{array}{r}
C_{c, o}=\frac{1}{4}\left[\frac{\varepsilon_{0} \varepsilon_{r} \pi\left(r^{2}-(r-c)^{2}\right)}{h}+\varepsilon_{0} \varepsilon_{r} r\left(\ln \frac{16 \pi r}{h}-1\right)\right. \\
\left.\quad-\varepsilon_{0} \varepsilon_{r}(r-c)\left(\ln \frac{16 \pi(r-c)}{h}-1\right)\right]
\end{array}
$$




$$
\begin{aligned}
C_{C, i}= & \frac{1}{4}\left[\frac{\varepsilon_{0} \varepsilon_{r} \pi\left((r-c-d)^{2}-(r-2 c-d)^{2}\right)}{h}+\varepsilon_{0} \varepsilon_{r}(r-c-d)\right. \\
& \left.\bullet\left(\ln \frac{16 \pi(r-c-d)}{h}-1\right)-\varepsilon_{0} \varepsilon_{r}(r-2 c-d)\left(\ln \frac{16 \pi(r-2 c-d)}{h}-1\right)\right]
\end{aligned}
$$

where $\varepsilon_{r}$ and $h$ are the real part of the permittivity and the thickness of the substrate, respectively. $r, c$ and $d$ correspond to the dimensions of the rings (Fig. 2a). These relationships were obtained from Kirchhoff's formula used in [18] to compute the approximate parallel-plate disk capacitance, except for the empirical factor (1/4), which was determined after several electromagnetic simulations.

\subsection{Simulations}

In order to verify the proposed equivalent circuit model of the DOSRR unit cell (Fig. 2) for different values of external radius ( $r=2.2 \mathrm{~mm}$ to $r=2.5 \mathrm{~mm}$ ), substrate thickness ( $h$ $=0.254 \mathrm{~mm}$ and $h=0.635 \mathrm{~mm})$ and relative permittivity $\left(\varepsilon_{r}=5\right.$ and $\left.\varepsilon_{r}=10.2\right)$, circuit and electromagnetic simulations have been carried out by using the commercial Agilent ADS and Ansoft HFSS simulators, respectively. For both simulation types, we have assumed the different DOSRR structures to be lossless $(R=0 \Omega)$ with the following fixed data: $c=0.3 \mathrm{~mm}, d=0.25 \mathrm{~mm}, g=0.5 \mathrm{~mm}$ and $D=9 \mathrm{~mm}$. The characteristic impedance of the microstrip line was $50 \Omega$. The values of the transmission pole $\left(f_{p}\right)$ and zero $\left(f_{z}\right)$ frequencies are plotted in Fig. 3 and Fig. 4, respectively. Table 1 lists the $L C$ values used during the simulations of the equivalent circuit model. According to these simulations, the transmission zero appears above the transmission pole. The average relative error obtained between circuit and electromagnetic simulations for the 
transmission pole $\left(f_{p}\right)$ frequency (Fig. 3) is lower than $4 \%$, whereas for the transmission zero ( $\left.f_{z}\right)$ frequency (Fig. 4 ), the average relative error is lower than $1.4 \%$.

Compact slow-wave type band-pass filters can be designed by cascading several DOSRR cells in series with a microstrip line. Thus, to evaluate the possibilities and to find out the properties of these filters, we have simulated the responses of several filters and compared them with those filters using OSRR cells. Fig. 5 shows the circuit (dotted lines) and electromagnetic (solid lines) simulation results $\left(S_{21}\right)$ obtained for one DOSRR cell and three cascaded DOSRR cells. In this same Fig. 5, we have also plotted the electromagnetic simulation results for the respective band-pass filters using OSRR cells. To find out the proprieties of these DOSRR-based filters, we have also simulated the insertion losses of several filters by using equivalent circuit model of Fig. $2 c$, varying the number $N$ of cells and the length $D$. The results are presented in Fig. 6 . The characteristic impedance of the microstrip lines and the relative permittivity of substrate were $\mathrm{Z}_{\mathrm{C}}=50 \Omega$ and $\varepsilon_{r}=10.2$, respectively. The dimensions of the OSRR cells were preserved with respect to the dimensions of the DOSRR cells. The OSRRs and DOSRRs were assumed lossless $(R=0 \Omega)$ and the circuit model values were: $L=7.487$ $\mathrm{nH}, C=0.864 \mathrm{pF}, C_{C, o}=0.165 \mathrm{pF}$ and $C_{c, i}=0.132 \mathrm{pF}$. As can be seen in Fig. 5, a good agreement between circuit and electromagnetic simulations of the DOSRR-based filters is obtained up to the transmission zero frequency. At higher frequencies, discrepancies appear, since the equivalent circuit model is simpler. This does not take into account the high-order effects. With respect to the OSRR-based filters (Fig. 5), the DOSRR-based filters present a bandwidth reduction. Each OSRR and DOSRR cell provides a transmission pole to the filter. Moreover, the DOSRR cell adds a transmission zero above the first transmission band. For both filters, the depth of the 
rejection band depends on the number of cascaded cells. However, the OSRR-based filter requires adding more cascaded OSRR cells (and therefore a larger filter size to obtain the same benefits) than the DOSRR-based filter in the rejection band. On the other hand, it can be seen in Fig. 6 that the previous equivalent circuit model element values for the DOSRR lead to a resonance and zero frequencies about $2 \mathrm{GHz}$ and 3.5 GHz, respectively. The bandwidth of the DOSRR-based filter can be controlled by adjusting the length $D$ of the unit cell, whereas the sharp cutoff of the upper side of the pass-band depends on the number $N$ of cascaded cells used for the implementation of the filter. The DOSRR cell offers the possibility of compact band-pass filters. At the resonance frequency $f_{0}=2 \mathrm{GHz}$, the wavelength in the microstrip line is approximately $\lambda=58 \mathrm{~mm}\left(\varepsilon_{\text {reff }}=6.7\right)$ and the length of the filter is $\lambda / 2$ for $D=9$ $\mathrm{mm}, N=3$ and two $50 \Omega$ microstrip sections of $1 \mathrm{~mm}$.

\section{Microstrip band-pass filters based on DOSRRs}

Two band-pass filters with the line-OSRR-DOSRR-OSRR-line and line-DOSRRDOSRR-DOSRR-line configurations have been fabricated on an Arlon AD1000 material $\left(\varepsilon_{r}=10.2, \operatorname{tg} \delta=0.0023\right.$ at $10 \mathrm{GHz}, h=0.635 \mathrm{~mm}$, copper thickness $t=17.5$ $\mu \mathrm{m})$ and measured. The design specifications were a first transmission pole around 2 GHz, a $3 \mathrm{~dB}$ bandwidth around $50 \%$ and a transmission zero around $3.5 \mathrm{GHz}$. The dimensions of both filters were obtained from equivalent circuits of the DOSRR (Fig. 2) and OSRR [8] cells with the following electrical parameters: $L=7.487 \mathrm{nH}, C=0.864$ $\mathrm{pF}, C_{C, o}=0.165 \mathrm{pF}$ and $C_{C, i}=0.132 \mathrm{pF}$. The layout and dimensions of the lineDOSRR-DOSRR-DOSRR-line filter are depicted in Fig. 7. The dimensions of the Fig. 7 were preserved for the line-OSRR-DOSRR-OSRR-line filter. 
The measurements were performed with a Rohde \& Schwarz ZVL6 (9 kHz - 6 $\mathrm{GHz}$ ) vector network analyzer (VNA) and Anritsu 3680K on-microstrip test fixture calibrated from $0.01 \mathrm{GHz}$ to $6 \mathrm{GHz}$. The measurements of the band-pass filters with the line-OSRR-DOSRR-OSRR-line and line-DOSRR-DOSRR-DOSRR-line configurations are, respectively, presented in Fig. 8 and Fig. 9 with solid lines. In these figures, we have also plotted the circuit model and electromagnetic simulation (HFSS) data results with dotted and dashed lines, respectively.

Fig. 8 and Fig. 9 show a good agreement between circuit simulation and measured results as the frequency is lower than $4 \mathrm{GHz}$. At higher frequencies, a spurious band appears as expected for this kind of filter. The equivalent circuit models fail, since numerous phenomena (mutual inductances, higher-order resonance, etc.) are not taken into account in the circuit models. However, these equivalent circuit models can be a useful tool for the initial design of these filters. All phenomena are reasonably considered in the electromagnetic simulations. The possibilities of the DOSRR cell are evident, since a unique cell located between two OSRR cells (Fig. 8) adds a transmission pole and a transmission zero above the first transmission band, which increases the depth of the rejection band without augmenting the number of stage and the size of the filter. Both configurations of filters achieve a first transmission pole around $2 \mathrm{GHz}$ and a $3 \mathrm{~dB}$ bandwidth of approximately $1 \mathrm{GHz}$. Transmission zeros are evident around $3.5 \mathrm{GHz}$ for both filters. These characteristics correspond to the initial specifications of design. They are obtained by adjusting the dimensions $(r, c, d)$ and the length $D$ of the cells. The band-pass filter with three cascaded DOSRR cells (Fig. 9) achieves a cutoff of the upper side of the pass-band sharper than in the case of the band- 
pass filter with the line-OSRR-DOSRR-OSRR-line configuration (Fig. 8), while the spurious band appears more close to the first transmission band for the first structure (three cascaded DOSRR cells). The presence of spurious band at frequencies above the transmission zero spoils the performance of the designed band-pass filters. In the next section, we present two strategies to improve the out-of-band rejection of these filters.

\section{Microstrip band-pass filters based on DOSRRs with spurious rejection}

The previous DOSRR-based microstrip band-pass filters have a spurious band like many planar band-pass filters that include resonators [8]. It would be interesting if the spurious band can be suppressed in order to improve the out-of-band rejection of these band-pass filters. A low-pass filter or a stop-band filter may be cascaded with these filters to suppress the spurious band at the cost of higher insertion losses and larger filter size. To overcome these drawbacks, we present two strategies that allow one to preserve the filter size and to improve the out-of-band rejection without adding any other component. These two strategies are applied to the previous band-pass filter with three cascaded DOSRR cells, whose spurious band is worse than the band-pass filter with the line-OSRR-DOSRR-OSRR-line configuration, to demonstrate its efficiency. The first strategy resides in reproducing the same circular design shape of the DOSRR cell at the top and bottom planes. Thus, in the ground plane of the unit DOSRR cell, we have substituted the square window without metallization by a circular window without metallization. The layout with the dimensions of the novel DOSRR-based microstrip band-pass filter is illustrated in Fig. 10. Previous electromagnetic simulations have shown that the bandwidth of these filters can be controlled by adjusting the diameter of the circular window, and that the bandwidth is preserved when the dimensions of the 
square and circular windows are the same. Thus, we have fixed the diameter of the circular window ( $\phi=9 \mathrm{~mm}$ ) to the dimension of the square window of the previous band-pass filter $(D=9 \mathrm{~mm})$ in order to keep the same bandwidth and to carry out a later comparison. The second approach consists in making U-shape slots in the transmission line in order to add extra transmission zeros to the DOSRR-based microstrip band-pass filter [15]. These extra transmission zeros can be adjusted to reject the spurious band and thus help to improve the out-of-band region of the DOSRR-based microstrip bandpass filter with circular windows. The layout with the dimensions of the DOSRR-based microstrip band-pass filter combining both strategies is shown in Fig. 11. The dimensions of the U-shape slots in the transmission line were previously calculated from simulated results of the DOSRR-based microstrip band-pass filter with circular windows (Fig. 10). Thus, two U-shape slots with different lengths were designed to reject two spurious frequencies about $4.8 \mathrm{GHz}$ and $5.7 \mathrm{GHz}$. The filters of Fig. 10 and Fig. 11 were fabricated by using the same above substrate (Arlon AD1000) and measured from $0.01 \mathrm{GHz}$ to $6 \mathrm{GHz}$ with the same above measurement system (R \& S VNA connected to the Anritsu 3680K on-microstrip test fixture).

The electromagnetic simulations and measurements of the band-pass filters illustrated in Fig. 10 and Fig. 11 are given in Fig. 12 and Fig. 13, respectively. The simulated (dashed lines) and measured (solid lines) results present a good agreement throughout the frequency range. These results are compared with those previously presented in Fig. 9, corresponding to the band-pass filter with three cascaded DOSRR cells and square windows at the bottom plane (Fig. 7). It can be seen that the $3 \mathrm{~dB}$ bandwidth is the same for the three band-pass filters designed in Figs. 7, 10 and 11 with the same dimension of square and circular windows $(\phi=D=9 \mathrm{~mm})$. The first and 
second spurious frequencies measured about $3.8 \mathrm{GHz}$ and $4.7 \mathrm{GHz}$ in Fig. 9 are shifted about 4.8 GHz and $5.7 \mathrm{GHz}$ in Fig. 12. Thus, our first strategy ensures that the spurious band is shifted upwards, achieving a rise of the stop band of approximately $1 \mathrm{GHz}$ with a rejection greater than $20 \mathrm{~dB}$ between $3.02 \mathrm{GHz}$ and 4.6 GHz. In Fig. 13, the DOSRRbased microstrip band-pass filter combining both strategies achieves good characteristics in the band-pass region and good rejection in the out-of-band region. The first and second spurious frequencies measured about $4.8 \mathrm{GHz}$ and $5.7 \mathrm{GHz}$ in Fig. 12 are attenuated over $10 \mathrm{~dB}$ in Fig. 13, with the help of the extra transmission zeros added with the two U-shape slots in the transmission line.

\section{Conclusion}

A double-sided open split ring resonator (DOSRR) connected in series with a microstrip line has been proposed and analyzed. With respect to the open split ring resonator (OSRR), the DOSRR cell has the capacity to add transmission zero above transmission pole, which improves the rejection depth without increasing the filter size. The DOSRR cell could be useful in the design of compact band-pass filters in planar technology. Thus, microstrip band-pass filters with cascaded DOSRRs and OSRRs have been designed, fabricated and measured. The filters were designed by using simple circuit models. The measurement results have confirmed the circuit and electromagnetic simulation results up to frequencies around the transmission zeros. At higher frequencies, a spurious band appears and reduces the stop band. Then, circular windows etched in the bottom plane instead of square windows and U-shape slots etched in the microstrip transmission line have been designed to increase the stop band, to suppress the spurious band and to save filter size. These two strategies have been applied to a 
compact band-pass filter with three cascaded DOSRRs and the measured results demonstrated their effectiveness.

\section{Acknowledgment}

The authors gratefully acknowledge Ministerio de Ciencias e Innovación of Spain for financial support of this work under the grant no.: TEC2010-21520-C04-04/TCM. 


\section{$7 \quad$ References}

[1] Pendry, J.B., Holden, A.J., Ribbins, D.J., and Stewart W.J.: 'Magnetism from conductors and enhanced nonlinear phenomena', IEEE Trans. Microw. Theory Tech., 1999, 47, (11), pp. 2075-2084

[2] Falcone, F., Lopetegi, T., Baena, J.D., Marqués, R., Martín, F., and Sorolla, M.: 'Effective negative- $\varepsilon$ stop-band microstrip lines based on complementary split ring resonators', IEEE Microw. Wirel. Compon. Lett., 2004, 14, (6), pp. 280-282

[3] Gil, M., Bonache, J., García-García, J., and Martín, F.: 'Miniaturization of planar microwave circuits by using resonant-type left-handed transmission lines', IET Microw. Antennas Propag., 2007, 1, (1), pp. 73-79.

[4] Roglá, L.J., Carbonel, J., and Boria, V.E.: 'Study of equivalent circuits for openring and split-ring resonators in coplanar waveguide technology', IET Microw. Antennas Propag., 2007, 1, (1), pp. 170-176.

[5] Gil, M., Bonache, J., and Martín F.: 'Synthesis and applications of new left handed microstrip lines with complementary split-ring resonators etched on the signal strip’, IET Microw. Antennas Propag., 2008, 2, (4), pp. 324-330.

[6] Liu, J.-C., Shu, D.-S., Zeng, B.-H., and Chang D.C.: 'Improved equivalent circuits for complementary split-ring resonator-based high-pass filter with C-shaped couplings’, IET Microw. Antennas Propag., 2008, 2, (6), pp. 324-330. 
[7] Li, C., and Li, F.: 'Microstrip bandpass filters based on zeroth-order resonators with complementary split ring resonators', IET Microw. Antennas Propag., 2009, 3, (2), pp. 276-280.

[8] Martel, J., Marqués, R., Falcone, F., Baena, J.D., Medina, F., Martín, F., and Sorolla, M.: 'A new LC series element for compact bandpass filter design', IEEE Microw. Wirel. Compon. Lett., 2004, 14, (5), pp. 210-212

[9] Martel, J., Bonache, J., Marqués, R., Martín, F., and Medina, F.: 'Design of wide-band semi-lumped bandpass filters using open split ring resonators', IEEE Microw. Wirel. Compon. Lett., 2007, 17, (1), pp. 28-30

[10] Vélez, A., Aznar, F., Bonache, J., Velázquez-Ahumada, M.C., Martel, J., and Martín, F.: 'Open complementary splits ring resonators (OCSRRs) and their application to wideband CPAW band pass filters', IEEE Microw. Wirel. Compon. Lett., 2009, 19, (4), pp. 197-199

[11] Vélez, A., Aznar, F., Durán-Sindreu, M., Bonache, J., and Martín, F.: 'Stop-band and band-pass filters in coplanar waveguide technology implemented by means of ellectrically small metamaterial-inspired open resonators', IET Microw. Antennas Propag., 2010, 4, (6), pp. 712-716.

[12] Marqués, R., Martín F., and Sorrolla, M.: 'Metamaterials with negative parameters: Theory, design, and microwave applications' (John Wiley \& Sons, Hoboken, 2008). 
[13] Bonache, J., Gil, I., García-García, J., and Martín, F.: 'Novel microstrip bandpass filters based on complementary Split-ring resonators', IEEE Trans. Microw. Theory Tech., 2006, 54, (1), pp. 265-271

[14] Pozar, D.M.: ‘Microwave engineering’ (John Wiley \& Sons, New York, 1998)

[15] Cheng, D., Zheng, H.X., Feng, L.Y., and Gao, F.Y.: 'Investigation of compact second-order microstrip bandpass filter', Microw. Opt. Technol. Lett., 2010, 52, pp. 1970-1973.

[16] Baena, J.D., Marqués, R., and Medina, F.: 'Artificial magnetic metamaterial design by using spiral resonators', Phys. Rev. B, 2004, 69, (2004), pp 1-5

[17] Wu, Q., Wu, M.F., Mang, F.Y., Wu, J., and Li L.W.: 'Modeling the effects of an individual SRR by equivalent circuit method', Proc. IEEE AP-S Int Symp 1B, Washington DC, USA, Jul. 2005, pp. 631-634

[18] Stefens, P.F., and Van Dommelen, D.M.: 'The influence of edge effects on measurements of dielectric material characteristics', Proc. Microwave and high frequency heating, Cambridge, UK, Sept. 1995, pp. 1-4 


\section{Figure and table captions:}

Figure 1 OSRR structure excited by a microstrip line

$a$ Top view

$b$ Bottom view

$c$ Equivalent circuit

Figure 2 DOSRR structure excited by a microstrip line

$a$ Top view

$b$ Bottom view

$c$ Equivalent circuit

Figure 3 Transmission pole frequencies $\left(f_{p}\right)$ obtained from electromagnetic and equivalent circuit model simulations for the DOSRR unit cell according to different values of external radius ( $r$ ), substrate thickness $(h)$ and relative permittivity $\left(\varepsilon_{r}\right)$. Data: $Z_{C}=50 \Omega, c=0.3 \mathrm{~mm}, d=0.25 \mathrm{~mm}, g=0.5 \mathrm{~mm}$ and $D=9 \mathrm{~mm}$

Figure 4 Transmission zero frequencies $\left(f_{z}\right)$ obtained from electromagnetic and equivalent circuit model simulations for the DOSRR unit cell according to different values of external radius ( $r$ ), substrate thickness $(h)$ and relative permittivity $\left(\varepsilon_{r}\right)$. Data: $Z_{C}=50 \Omega, c=0.3 \mathrm{~mm}, d=0.25 \mathrm{~mm}, g=0.5 \mathrm{~mm}$ and $D=9 \mathrm{~mm}$

Table $1 \quad L C$ values of the different DOSRR equivalent circuit models used during the simulations 
Figure 5 Insertion loss results of several band-pass filters with cascaded DOSRR and OSRR cells (solid line: electromagnetic simulation and dotted line: equivalent circuit model simulation). Data: $Z_{c}=50 \Omega, \varepsilon_{r}=10.2, h=0.635 \mathrm{~mm}, r=2.2 \mathrm{~mm}, c=$ $0.3 \mathrm{~mm}, d=0.25 \mathrm{~mm}, g=0.5 \mathrm{~mm}$, and $D=9 \mathrm{~mm}$

Figure 6 Insertion loss results of several band-pass filters with cascaded DOSRR cells by using the equivalent circuit model of Fig. 2c. Data: $Z_{c}=50 \Omega, \varepsilon_{r}=10.2, h=$ $0.635 \mathrm{~mm}, r=2.2 \mathrm{~mm}, c=0.3 \mathrm{~mm}, d=0.25 \mathrm{~mm}, g=0.5 \mathrm{~mm}, D=9 \mathrm{~mm}$ (solid line) and $\mathrm{D}=14 \mathrm{~mm}$ (dotted line)

Figure $7 \quad$ Layout and dimensions ( $\mathrm{mm}$ ) of the fabricated band-pass filter with three cascaded DOSRRs

Figure 8 Simulated and measured S-parameters of the line-OSRR-DOSRR-OSRRline filter

a $S_{11}$-parameter

b $S_{21}$-parameter

Figure 9 Simulated and measured S-parameters of the line-DOSRR-DOSRRDOSRR-line filter

a $S_{11}$-parameter

$b S_{21}$-parameter 
Figure 10 Layout and dimensions ( $\mathrm{mm}$ ) of the fabricated band-pass filter with three cascaded circular DOSRRs

Figure 11 Layout and dimensions $(\mathrm{mm})$ of the fabricated band-pass filter with three cascaded circular DOSRRs and U-shape slots in the transmission line

Figure 12 Simulated and measured S-parameters for the filter of Fig. 9

Figure 13 Simulated and measured S-parameters for the filter of Fig. 10 
Figure $1 \mathrm{a}$

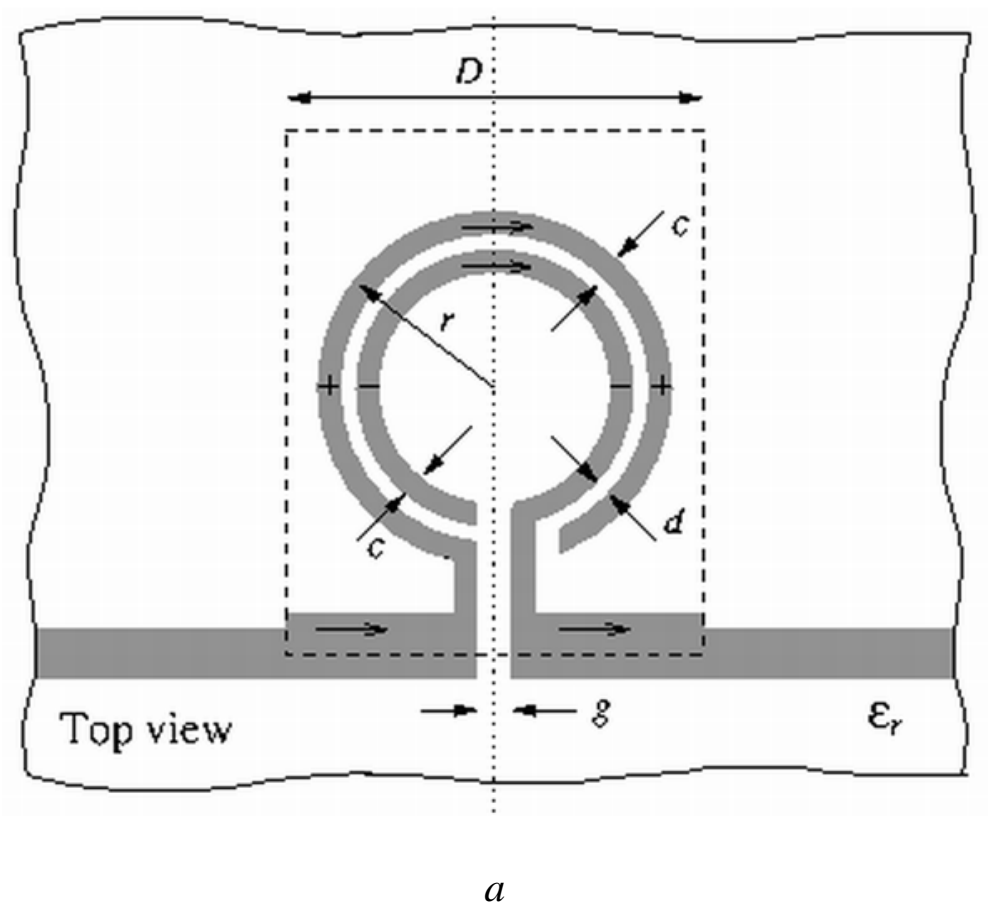


Figure $1 \mathrm{~b}$

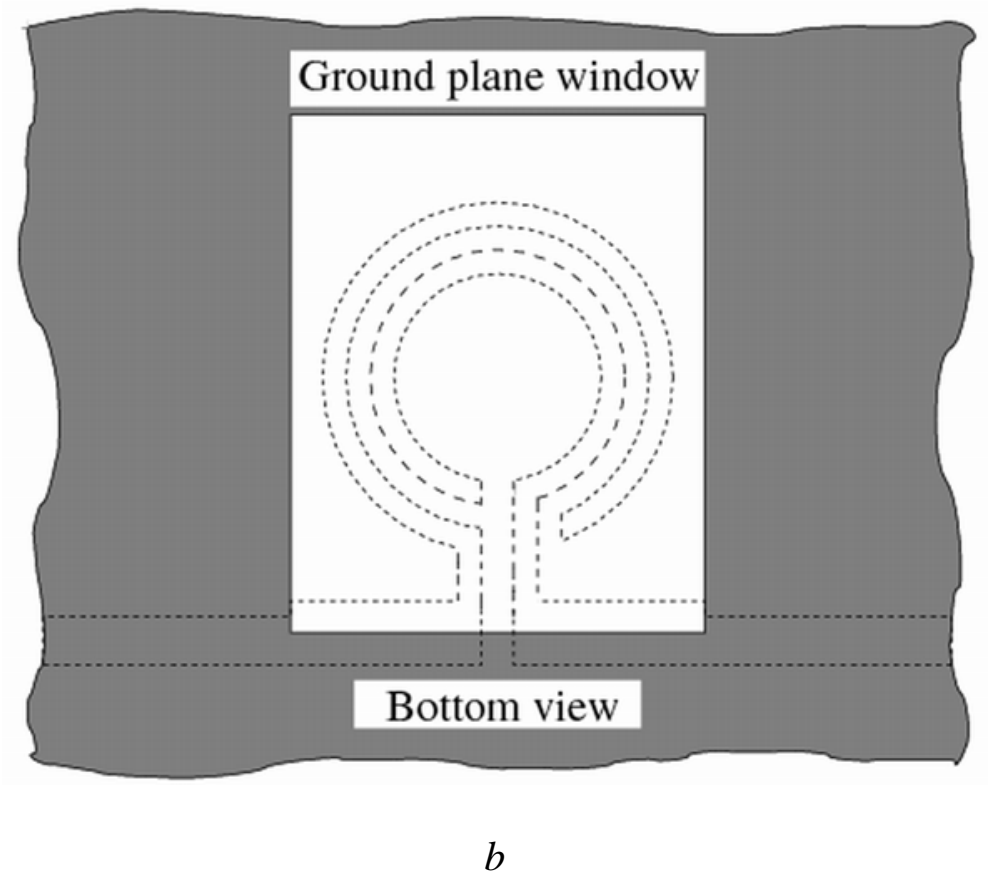


Figure 1 c

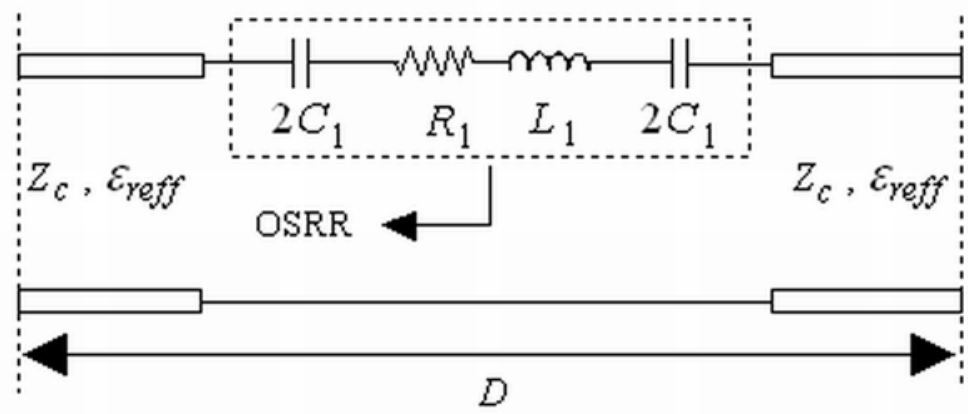

C 
Figure 2 a

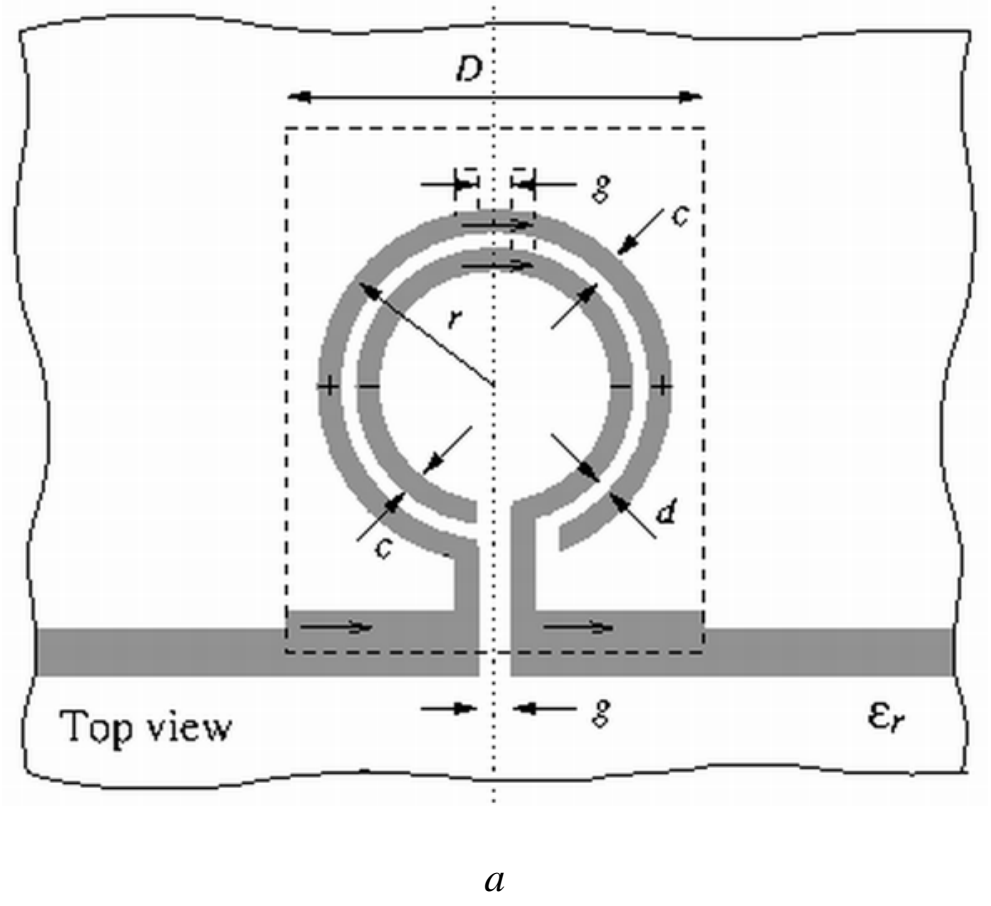


Figure $2 \mathrm{~b}$

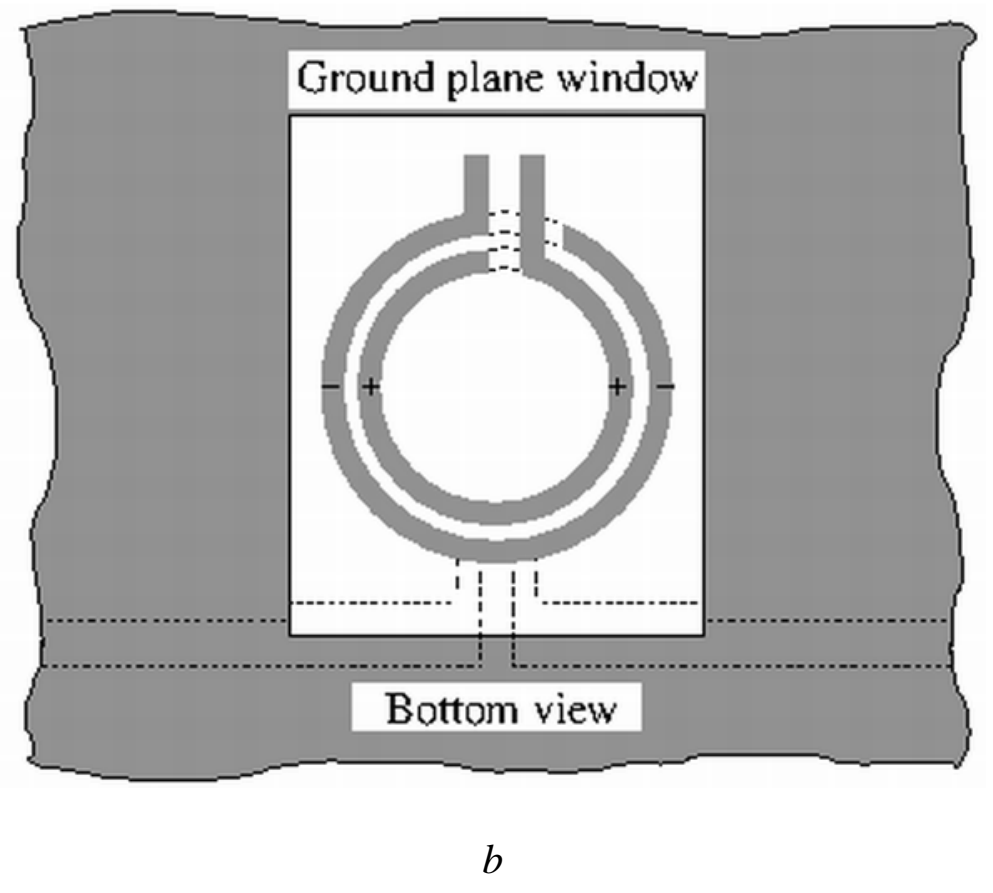


Figure 2 c

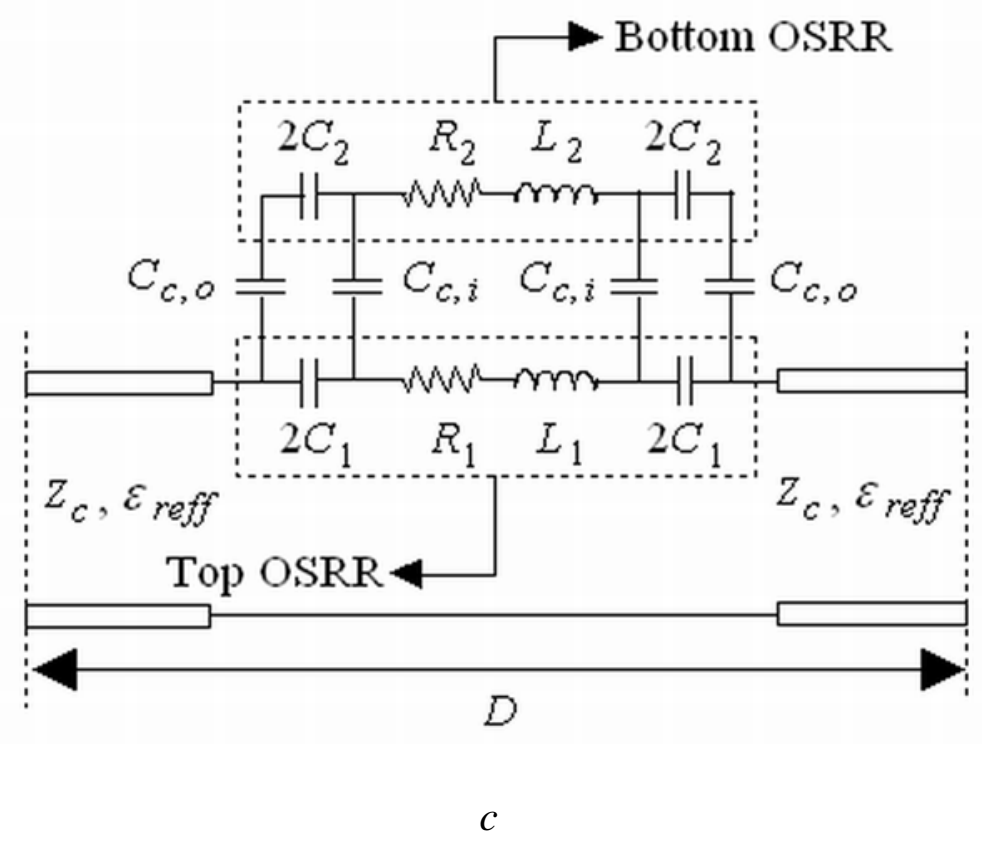


Figure 3

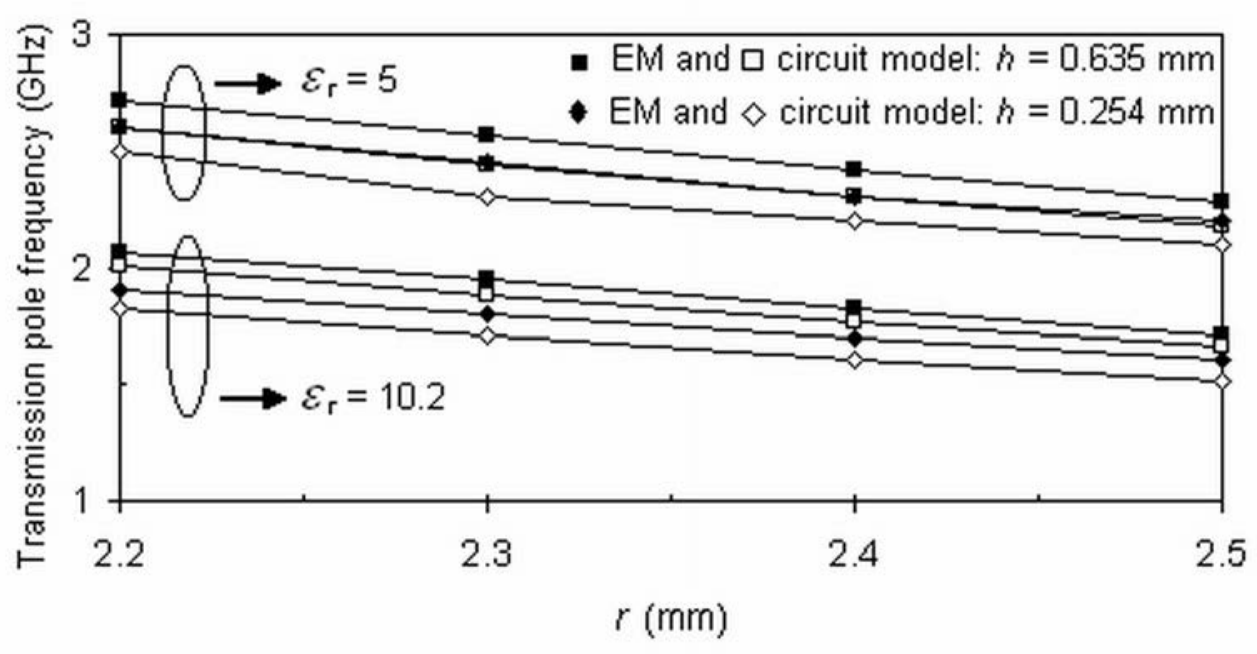


Figure 4

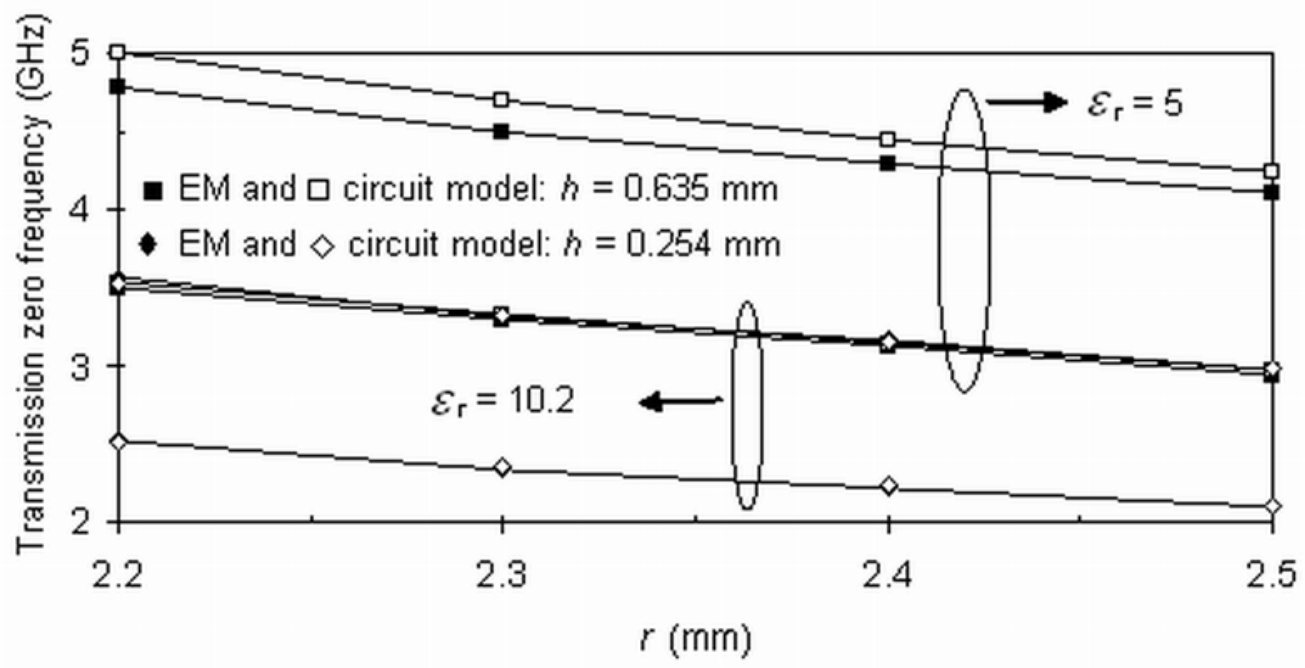


Table 1

\begin{tabular}{|c|c|c|c|c|c|c|c|c|}
\hline & \multicolumn{4}{|c|}{$\varepsilon_{r}=10.2$ and $h=0.635 \mathrm{~mm}$} & \multicolumn{4}{|c|}{$\varepsilon_{r}=10.2$ and $h=0.254 \mathrm{~mm}$} \\
\hline$r(\mathrm{~mm})$ & $L(\mathrm{nH})$ & $C(\mathrm{pF})$ & $C_{C, o}(\mathrm{pF})$ & $C_{C, i}(\mathrm{pF})$ & $L(\mathrm{nH})$ & $C(\mathrm{pF})$ & $C_{C, o}(\mathrm{pF})$ & $C_{C, i}(\mathrm{pF})$ \\
\hline 2.2 & 7.487 & 0.864 & 0.165 & 0.132 & 7.487 & 0.72 & 0.377 & 0.289 \\
\hline 2.3 & 8.038 & 0.916 & 0.172 & 0.14 & 8.038 & 0.76 & 0.394 & 0.306 \\
\hline 2.4 & 8.595 & 0.964 & 0.179 & 0.147 & 8.595 & 0.804 & 0.411 & 0.323 \\
\hline 2.5 & 9.158 & 1.012 & 0.186 & 0.154 & 9.158 & 0.844 & 0.428 & 0.34 \\
\hline & \multicolumn{4}{|c|}{$\varepsilon_{r}=5$ and $h=0.635 \mathrm{~mm}$} & \multicolumn{4}{|c|}{$\varepsilon_{r}=5$ and $h=0.254 \mathrm{~mm}$} \\
\hline$r(\mathrm{~mm})$ & $L(\mathrm{nH})$ & $C(\mathrm{pF})$ & $C_{C, o}(\mathrm{pF})$ & $C_{C, i}(\mathrm{pF})$ & $L(\mathrm{nH})$ & $C(\mathrm{pF})$ & $C_{C, o}(\mathrm{pF})$ & $C_{C, i}(\mathrm{pF})$ \\
\hline 2.2 & 7.487 & 0.468 & 0.081 & 0.065 & 7.487 & 0.404 & 0.185 & 0.142 \\
\hline 2.3 & 8.038 & 0.496 & 0.084 & 0.068 & 8.038 & 0.428 & 0.193 & 0.15 \\
\hline 2.4 & 8.595 & 0.52 & 0.088 & 0.072 & 8.595 & 0.452 & 0.201 & 0.158 \\
\hline 2.5 & 9.158 & 0.548 & 0.091 & 0.075 & 9.158 & 0.472 & 0.21 & 0.167 \\
\hline
\end{tabular}


Figure 5

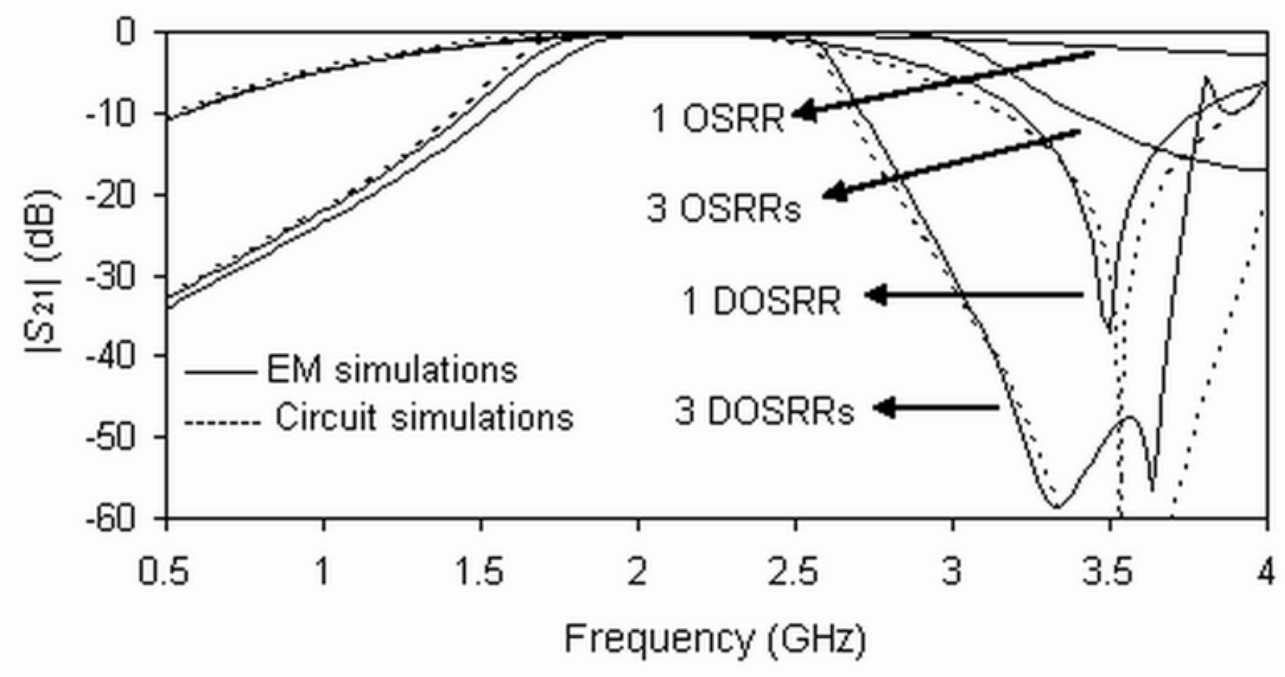


Figure 6

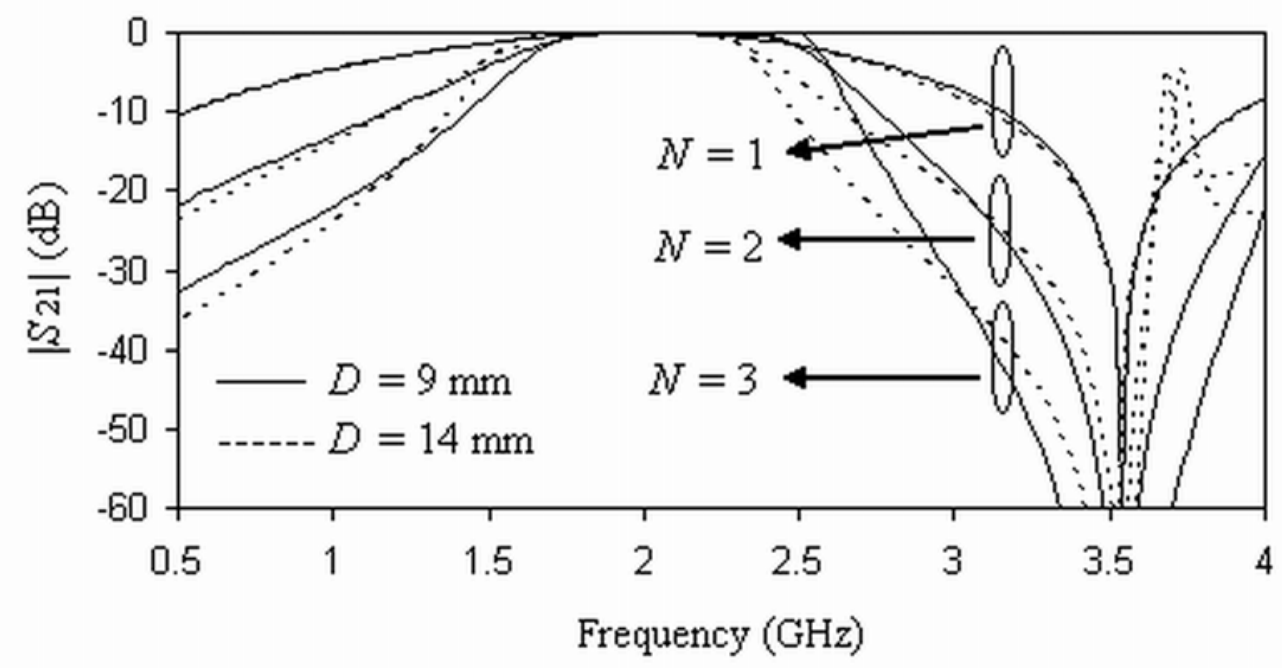


Figure 7

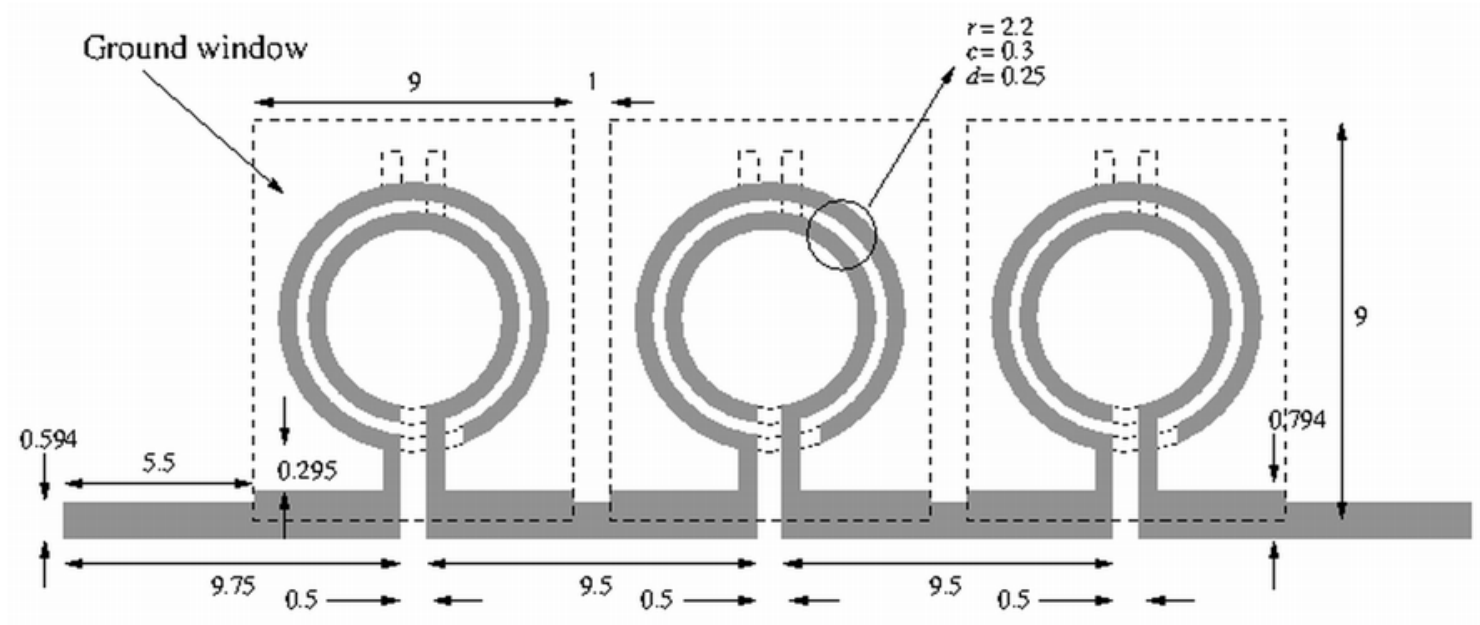


Figure $8 a$

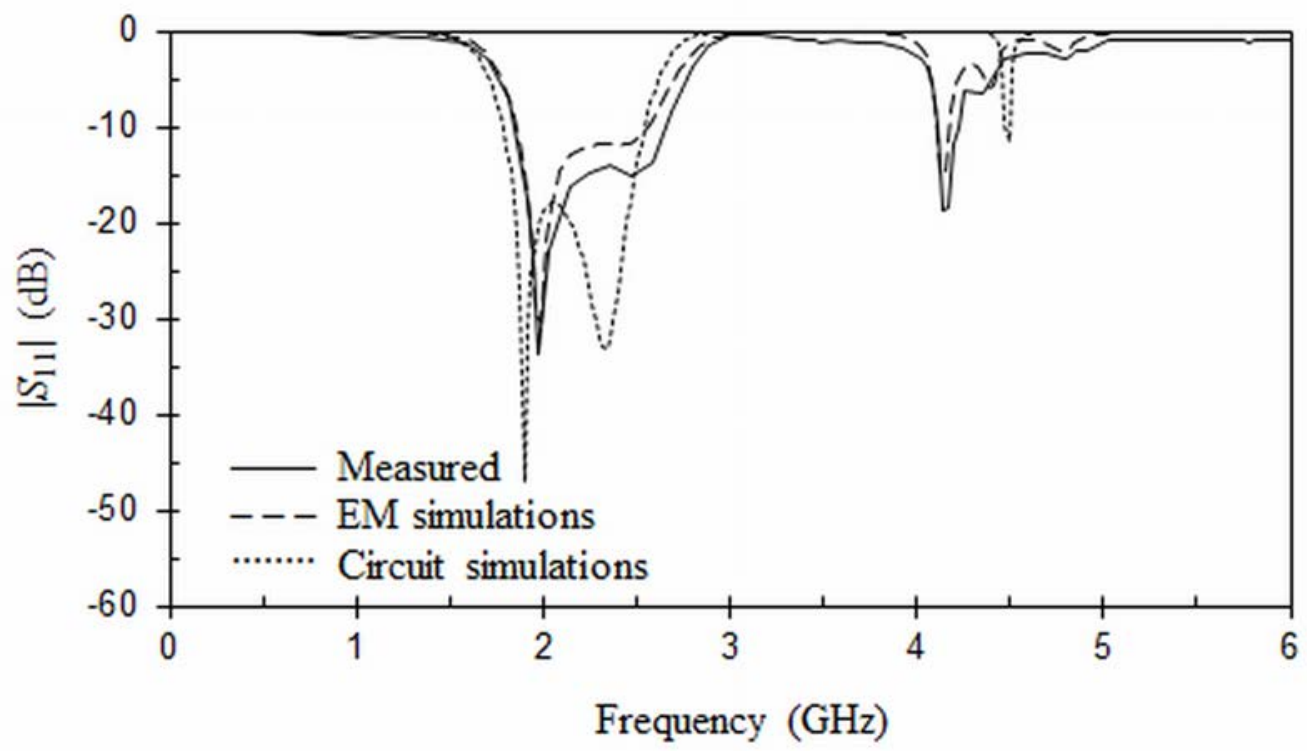

$a$ 
Figure $8 b$

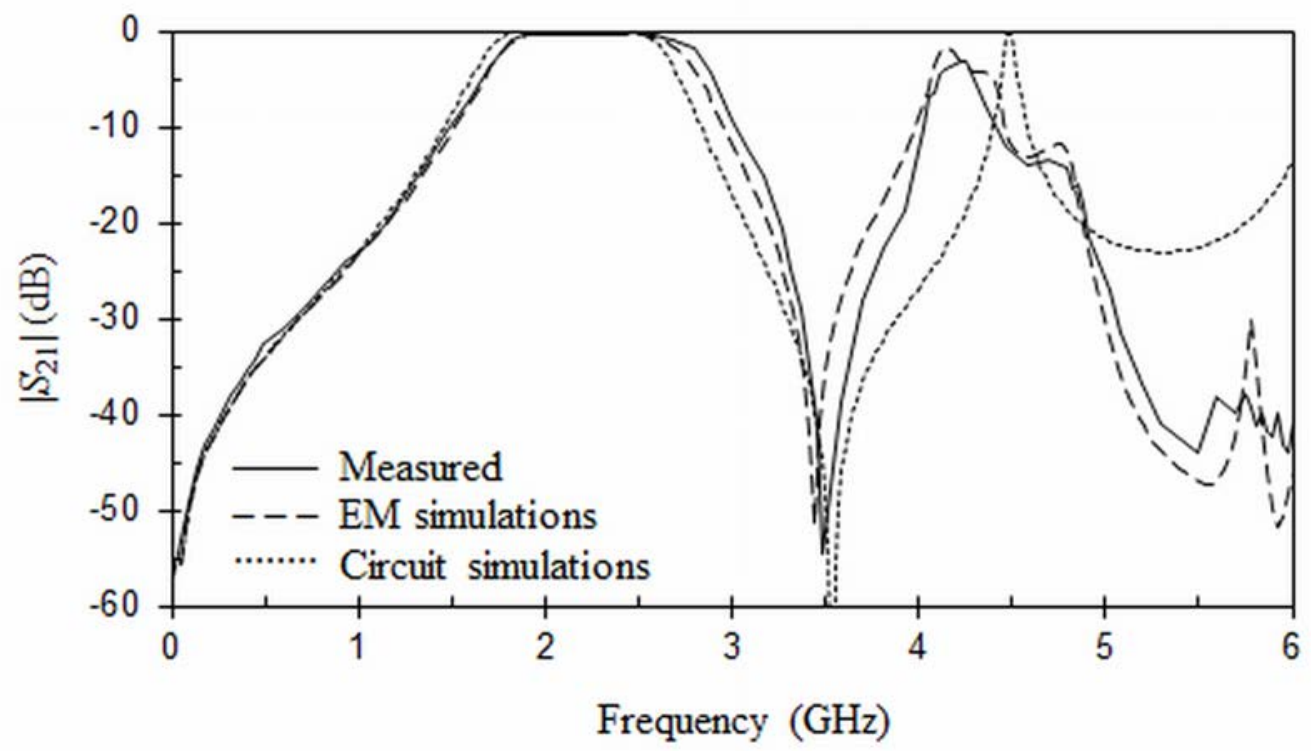

b 
Figure $9 a$

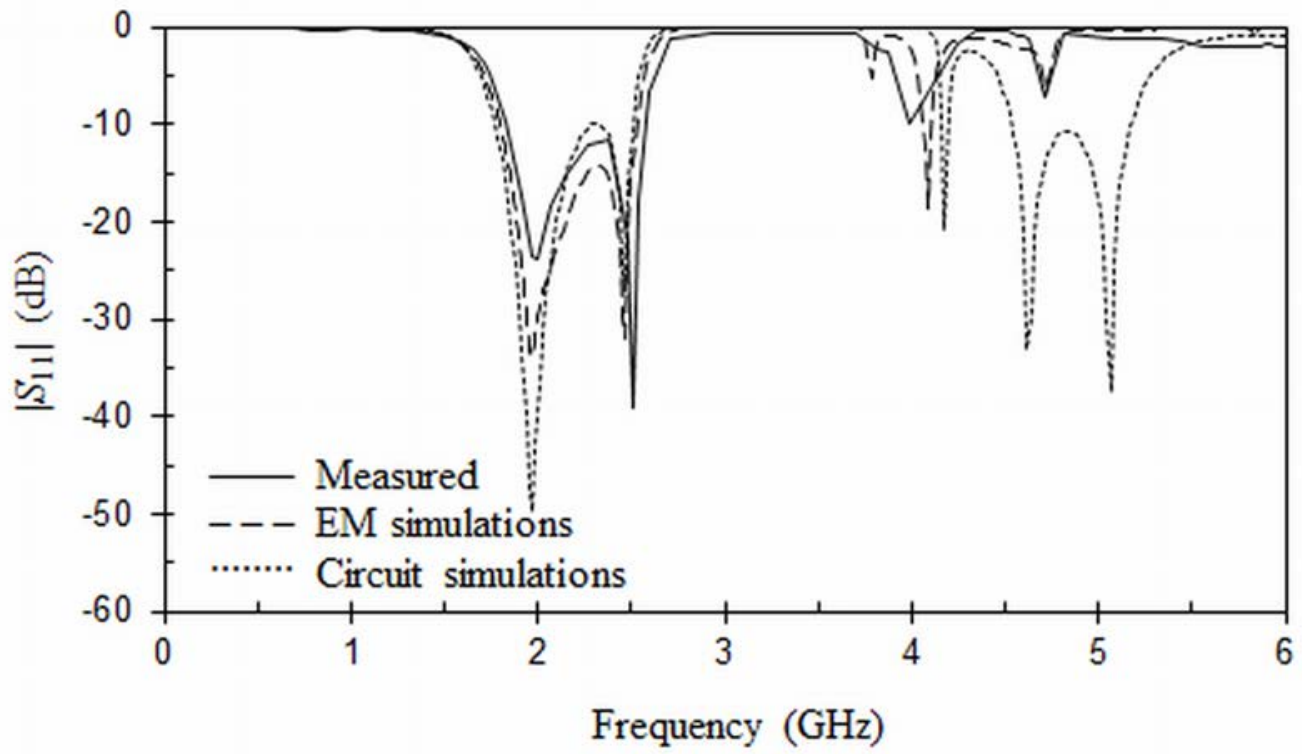

$a$ 
Figure $9 b$

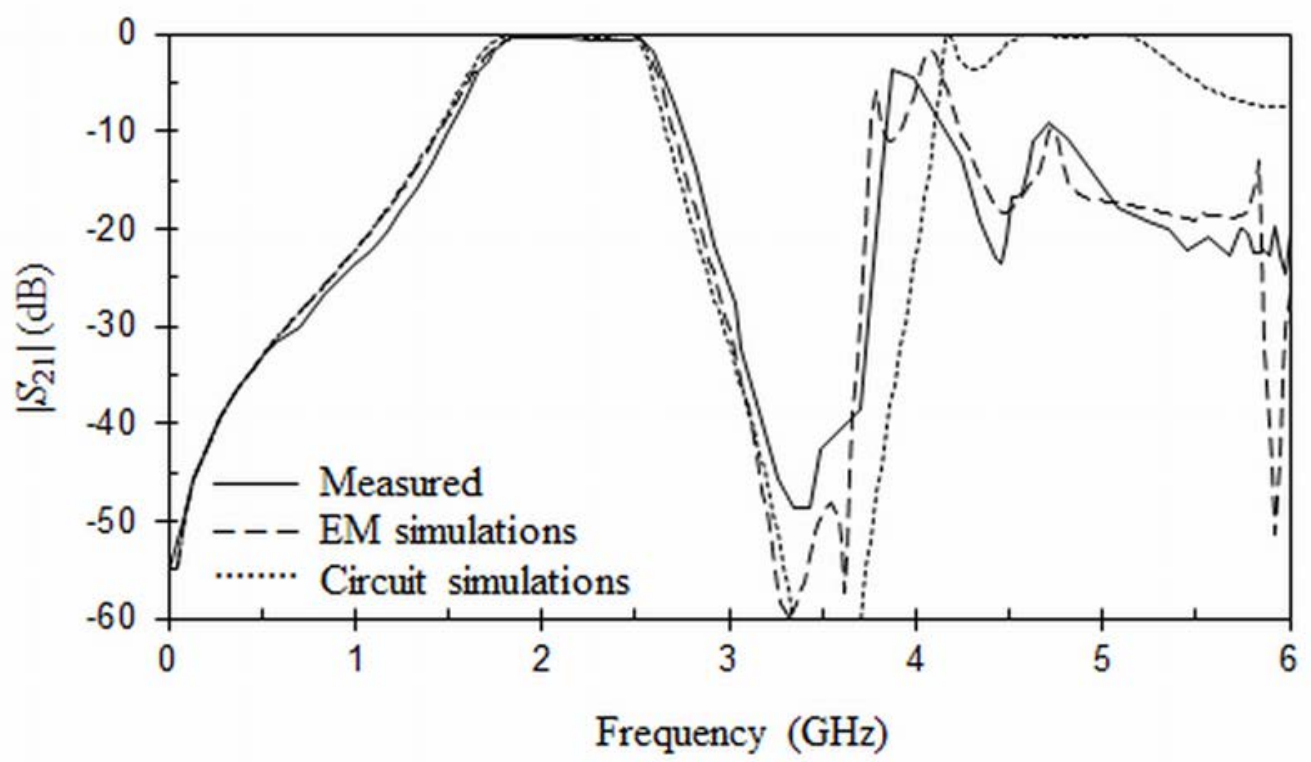

b 
Figure 10

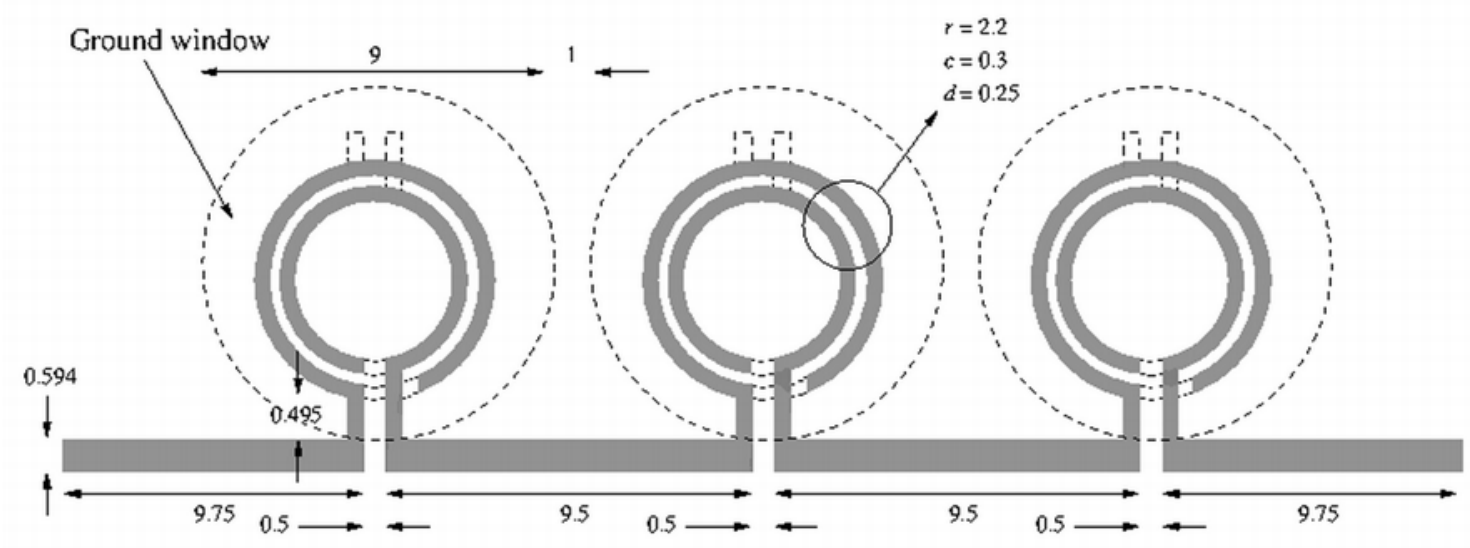


Figure 11

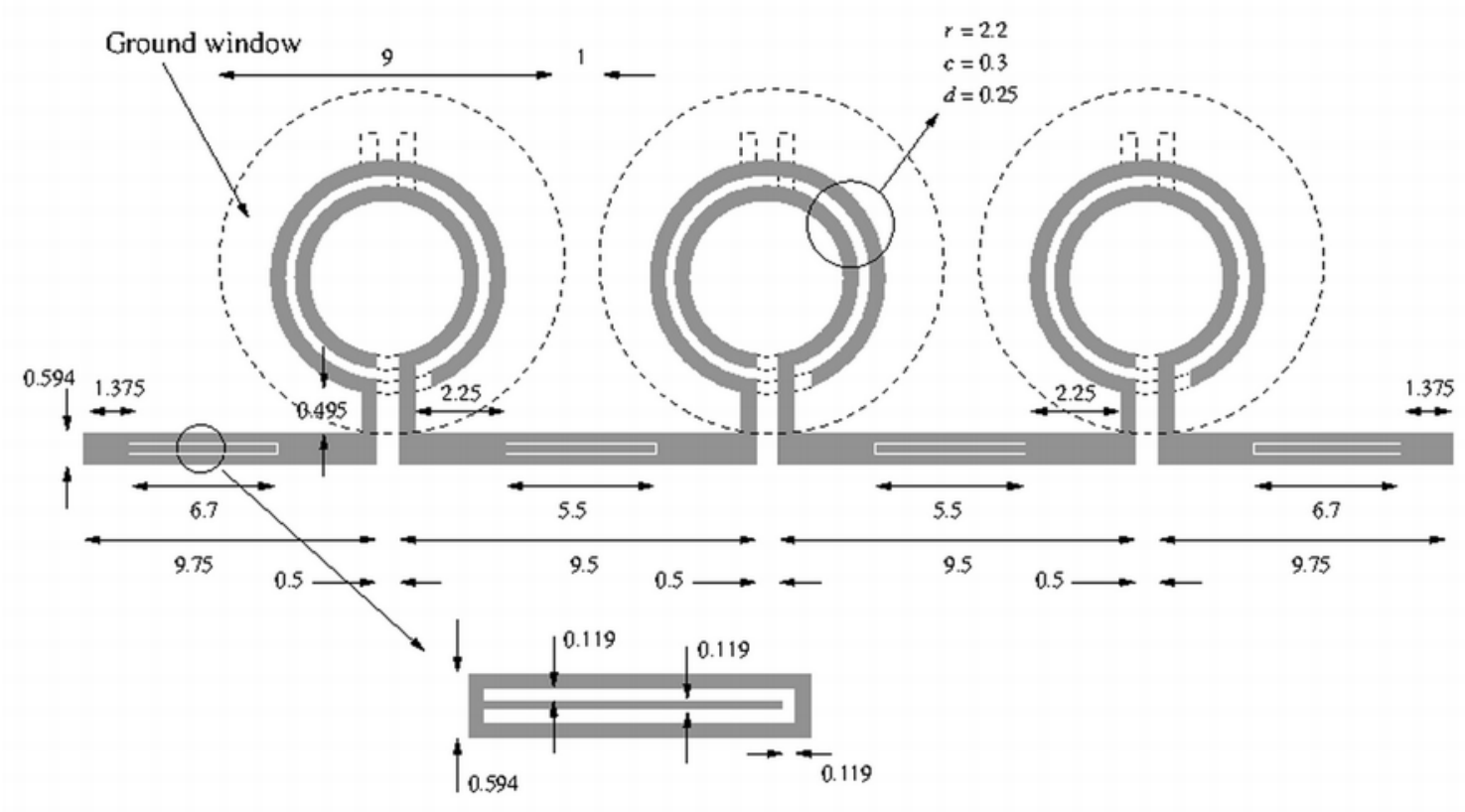


Figure 12

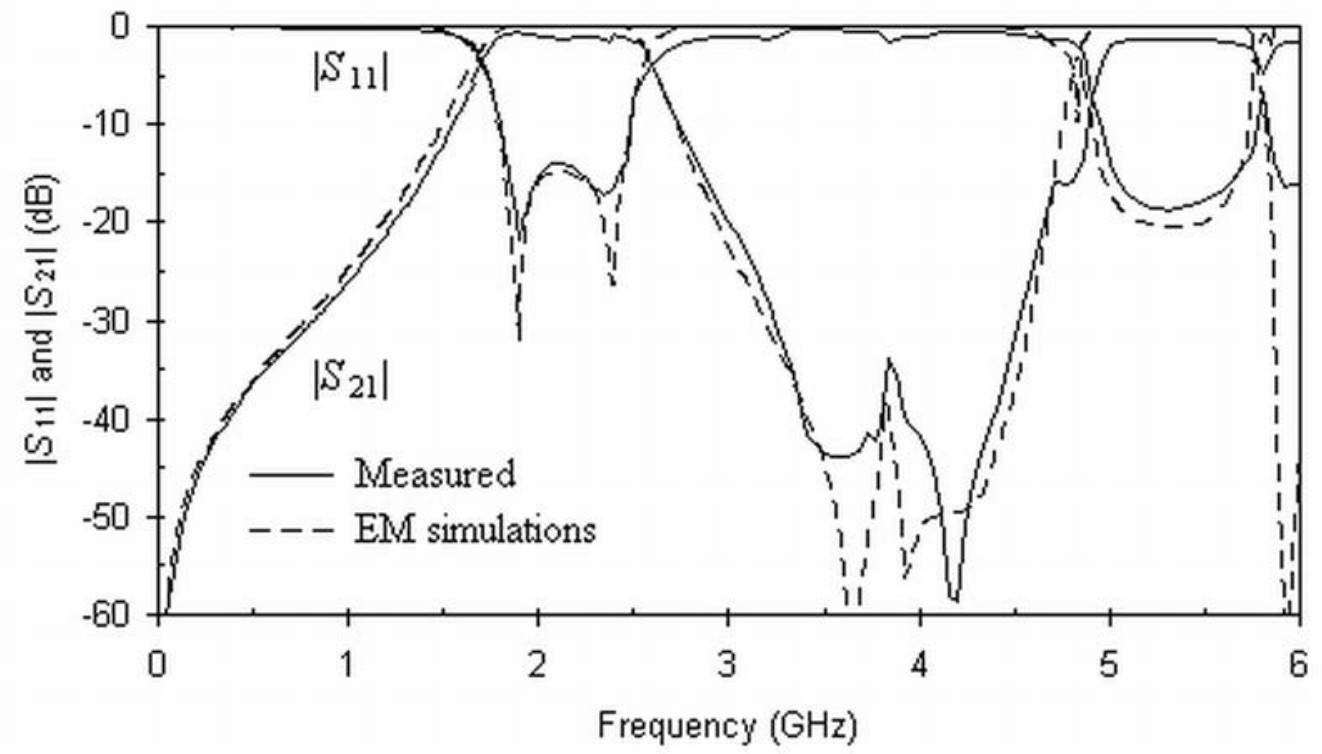


Figure 13

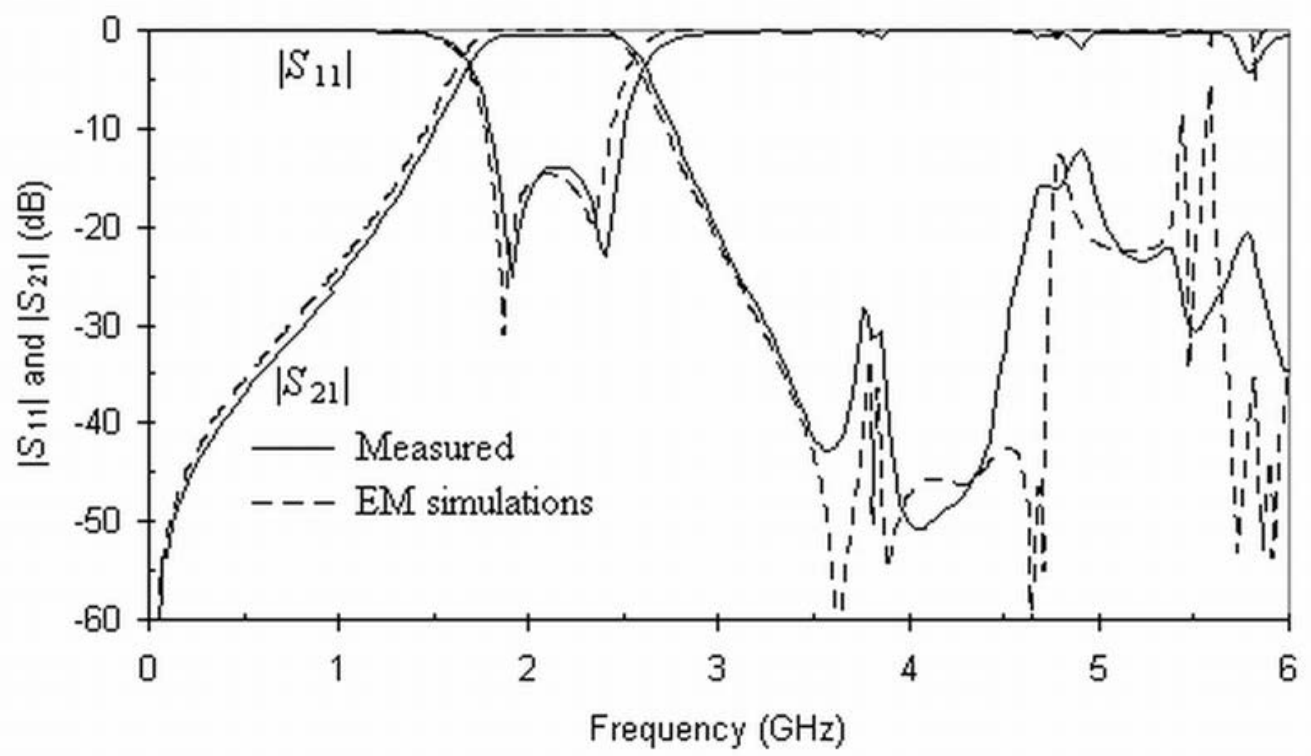

